\title{
OPTIMALISASI POTENSI SUMBERDAYA KELAUTAN DAN PERIKANAN SUMATERA BARAT MELALUI PEMETAAN KUALITAS SEKOLAH MENENGAH KEJURUAN (SMK) KEMARITIMAN
}

\author{
OPTIMIZING THE POTENTIAL OF MARINE AND \\ FISHERY RESOURCES OF WEST SUMATERA THROUGH \\ VOCATIONAL HIGH SCHOOL QUALITY MAPPING (SMK) \\ KEMARITIMAN
}

\author{
Dwi Astuti ${ }^{1}$ \\ ${ }^{1}$ Badan Penelitian dan Pengembangan Provinsi Sumatera Barat \\ Jl. Jenderal Sudirman No. 51 Padang Sumatera Barat \\ Email : dwiastuti280@gmail.com
}

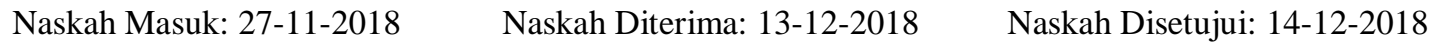

\begin{abstract}
West Sumatra has a large water area with very large potential of marine and fisheries resources but this potential cannot be utilized optimally and sustainably. One obstacle is due to the low quality of Human Resources (HR) in the maritime field. This study aims to map the quality of maritime Vocational Schools in West Sumatra Province in terms of various aspects including facilities and infrastructure, quality and quantity of teaching staff resources, funding and governance followed by policy recommendations for the Government of West Sumatra Province. This research was conducted in August - September 2017 using a qualitative descriptive approach. Data collection was carried out by in-depth interviews and observations in 5 (five) Maritime Vocational Schools in West Sumatra located in Padang City, Agam Regency, Padang Pariaman Regency. Pariaman City, West Pasaman Regency, and South Coastal District. The results showed that the quality of the 5 (five) maritime Vocational Schools was still below the standard when compared to the Middle Fisheries Business School (SUPM) in Padang Pariaman District. The recommendations and policies needed are: collaborating with Universities and Business World / Industrial World that are relevant to optimize facilities and infrastructure, appoint educators as the State Civil Apparatus (ASN) from relevant tertiary institutions and improve their competencies through expertise and financing training support in order to produce reliable maritime HR.
\end{abstract}

Keywords: Mapping, Maritime Affairs, and Vocational School

\begin{abstract}
ABSTRAK
Sumatera Barat memiliki wilayah perairan yang luas dengan potensi sumberdaya kelautan dan perikanan yang sangat besar namun potensi tersebut belum dapat dimanfaatkan secara optimal dan berkelanjutan. Salah satu kendalanya adalah karena rendahnya kualitas Sumber Daya Manusia (SDM) bidang Kemaritiman yang dihasilkan oleh SMK Kemaritiman di Sumatera Barat. Penelitian ini bertujuan untuk memetakan kualitas SMK Kemaritiman di Provinsi Sumatera Barat ditinjau dari berbagai aspek diantaranya sarana dan prasarana, kualitas dan kuantitas SDM tenaga pendidik dan pembiayaan. Penelitian ini dilaksanakan Bulan Agustus - September 2017 dengan menggunakan pendekatan deskriptif kualitatif. Pengumpulan data dilakukan dengan wawancara mendalam dan observasi di 5 (lima) SMK Kemaritiman di Sumatera Barat yang berlokasi di Kota Padang; Kota Pariaman; Kabupaten Pasaman Barat; Kabupaten Agam dan Kabupaten Pesisir Selatan dan SUPM sebagai standar yang berada di Kabupaten Padang Pariaman. Hasil penelitian menunjukkan bahwa kualitas ke 5 (lima) SMK Kemaritiman tersebut masih dibawah standar Sekolah Usaha Perikanan Menengah (SUPM). Rekomendasi dan kebijakan yang diperlukan adalah : melakukan kerjasama dengan Perguruan Tinggi dan Dunia Usaha/Dunia Industri yang relevan untuk mengoptimalkan sarana dan prasarana, mengangkat tenaga pendidik sebagai Aparatus Sipil Negara (ASN) dari perguruan tinggi yang relevan dan
\end{abstract}


meningkatkan kompetensinya melalui pelatihan keahlian serta pembiayaan yang mendukung agar menghasilkan SDM kemaritiman yang handal.

Kata Kunci: Pemetaan, Sekolah Menengah Kejuruan, Kemaritiman

\section{PENDAHULUAN}

Indonesia memiliki wilayah perairan yang sangat luas dengan potensi sumber daya kelautan yang melimpah sehingga perlu dikelola secara optimal dan berkelanjutan, pengelolaan sumber daya kelautan dilakukan dalam rangka mewujudkan cita-cita Indonesia sebagai poros maritim dunia dalam upaya memberikan manfaat yang sebesarbesarnya bagi kemakmuran rakyat. Namun potensi yang sangat besar dari kekayaan laut Indonesia ternyata belum mampu mensejahterakan para nelayan yang menjadi pelaku utama dalam pemanfaatan sumber daya perairan (Sudirman, 2006). Menurut data Badan Pusat Statistik (BPS) tahun 2012, penduduk miskin di Indonesia mencapai 34,96 juta jiwa dan $63,47 \%$ masyarakat hidup di kawasan pesisir dan pedesaan.

Indonesia sebagai negara dengan potensi yang besar saat ini, memiliki peluang sangat besar menjadi negara maju dengan memiliki tingkat perekonomian yang tinggi. karena selain kekayaan alam, bangsa Indonesia memiliki aset yaitu jumlah penduduk yang dapat menjadi modal dasar bagi peningkatan produktifitas ekonomi. Berdasarkan data BPS tahun 2012, jumlah penduduk Indonesia terus mengalami pertumbuhan yang cukup tinggi sehingga pada tahun 2010-2035 Indonesia memiliki penduduk dengan usia produktif yang cukup besar (Bonus Demografi)

Sumatera Barat yang berada di pesisir pantai barat Sumatera yang langsung berhadapan dengan Samudera Hindia memiliki perairan laut dan perairan umum, menyimpan potensi yang sangat besar untuk kepentingan ekonomi produktif maupun konservasi akan menjadikan andalan pembangunan masa depan. Pengelolaan potensi kelautan ini tentu membutuhkan tenagatenaga yang terampil dan sumber daya manusia kelautan yang berkualitas. Sekolah kemaritiman adalah salah satu lembaga penunjang yang diharapkan nantinya mampu mengoptimalkan pengolahan potensi sumber daya kelautan Sumatera Barat yang sangat potensial.

Memperhatikan data jumlah Sekolah Menengah Atas di Sumatera 
Barat sebanyak 505 sekolah terdiri dari SMA dan SMK Negeri dan swasta, untuk Sekolah Menengah Kejuruan di Sumatera Barat berjumlah sekitar 207 SMK, dan salah satu kelompok sekolah menengah kejuruan adalah SMK Kemaritimanan (Bidang Keahlian Kapal Niaga dan Bidang Keahlian Kapal Perikanan). Di Sumatera Barat jumlah SMK Kemaritiman dengan bidang keahlian perikanan masih kurang dibandingkan dengan luasnya potensi wilayah yang dapat diolah. SMK Perikanan yang tersebar di daerah pesisir pantai barat Provinsi Sumatera Barat ada 6 (enam), yaitu di Kota Padang, Kota Pariaman, Kabupaten Padang Pariaman, Kabupaten Pesisir Selatan, Kabupaten Agam dan Kabupaten Pasaman Barat.

Kendala dalam pengembangan SMK Kemaritiman saat ini adalah keberadaan guru, sarana dan prasarana dan pembiayaan, Khusus guru untuk SMK Kelautan dan Perikanan belum ada Perguruan Tinggi yang menghasilkan lulusan, betul-betul disiapkan untuk menjadi guru yang dibekali kompentensi ilmu keguruan dalam kejuruan tersebut.

Berdasarkan permasalahan tersebut, maka dilakukan kajian yang bertujuan untuk memetakan kualitas SMK kemaritiman di Sumatera Barat ditinjau dari aspek saran dan prasarana, guru serta pembiayaan.

\section{METODOLOGI}

Kajian ini bersifat deskriptif kualitatif yang dilaksanakan pada bulan Agustus - November 2018 di lima SMK yang terdapat di 5 (lima) kabupaten yakni SMKN 2 Painan, SMKN Tanjung Mutiara Agam, SMKN Sasak Pasaman Barat, SMKN 3 Pariaman dan SMKN 10 Padang dan Sekolah Umum Perikanan Menengah (SUPM) Padang Pariaman sebagai standar. Metode pengumpulan data primer melalui wawancara dan observasi. Wawancara dilakukan dengan Kepala Sekolah, Waka Sarana dan Prasarana dan Waka Kurikulum, Dinas Kelautan dan Perikanan dan Instansi terkait kemaritiman Kabupaten Padang Pariaman. Data sekunder lainnya diperoleh dari literatur review/penelusuran dokumen sekolah, buku, jurnal dan lain-lain.

\section{HASIL DAN PEMBAHASAN}

\section{Potensi Sumberdaya Kelautan}

\section{Sumatera Barat}

Sumatera Barat mempunyai potensi kelautan dan perikanan yang sangat besar, dengan luas perairan laut 
$52.882,42 \mathrm{~km}$, panjang garis pantai $2.543,80 \mathrm{~km}$ dan memiliki 375 pulau besar dan kecil. Potensi mangrove dan terumbu karang 39.832 ha dan $6.974,91$ ha. Selain itu juga terdapat potensi padang lamun dan rumput laut. Pengelolaan potensi kelautan di Sumatera Barat yang sangat besar, tentu membutuhkan tenaga-tenaga yang terampil dan sumber daya manusia kelautan yang berkualitas.

SMK Kemaritiman adalah satu satu sekolah menengah kejuruan yang di padang dapat menjadi jalan keluar atas pemasalahan yang dihadapi Inonesia dalam sektor maritim dan kelautan. SMK Kemaritiman di Sumatera Barat harus melirik potensi besar yang dimiliki kelautan Sumatera Barat.

\section{Kualitas Sekolah Menengah Kejuruan}

Dalam penjabaran UU No. 17 Tahun 2007 tentang RPJPN 2005-2025 salah satu tantangan Indonesia adalah rendahnya kualitas sumber daya manusia yang mengakibatkan rendahnya produktifitas dan daya saing bangsa, khusus untuk sektor pendidikan Indonesia dihadapi pada tantangan untuk menyediakan layanan pendidikan yang berkualitas. Untuk hal tersebut, pendidikan menengah merupakan titik kritis dalam pembangunan pendidikan di samping berkontribusi melanjutkan ke perguruan tinggi, sekaligus berkontribusi dalam penyediaan sumber daya manusia produktif, yang berkualitas, dan berdaya saing. (Salinan Undang-Undang Nomor 17 Tahun 2007 tentang RPJPN 2005-2025)

Peraturan Pemerintah No. 19 Tahun 2005 tentang Standar Nasional Pendidikan telah menetapkan acuan minimal berkualitas yang harus dipenuhi oleh satuan pendidikan dalam penyelenggaraan layanan pendidikan yang berkualitas. Acuan berkualitas tersebut telah menjabarkan seluruh aspek penyelenggaraan pendidikan yang meliputi standar kompetensi kelulusan, standar isi, standar proses, standar penilaian, standar pendidik dan tenaga kependidikan, standar sarana dan prasarana, standar pembiayaan dan standar pengelolaan pendidikan yang komprehensif sebagai landasan penyelenggaraan pendidikan untuk setiap jenjang pendidikan termasuk jenjang pendidikan menengah.

\section{SMK Kemaritiman di Sumatera Barat \\ Layanan pendidikan yang berkualitas pada SMK Kemaritimanan}


di Sumatera Barat hanya dapat diperoleh pada Sekolah Umum Perikanan Menengah (SUPM) Pariaman yang merupakan salah satu sekolah perikanan yang berada dibawah Kementerian Kelautan dan Perikanan RI, yang telah terdaftar di Direktorat Perhubungan Laut dan berstandar International Maritime Organization (IMO). SUPM Pariaman sesuai dengan keputusan Menteri Pendidikan Nasional RI, Nomor 129.a/U/2004 tentang Standar Pelayanan Minimal (SPM) bidang Pendidikan, pasal 4 dinyatakan SPM Guru SMK, sarana dan prasarana yang harus dipenuhi mencapai $80 \%$ dan $90 \%$ memiliki guru kualifikasi sesuai dengan kompetensi yang ditetapkan secara nasional. Hal ini karena SUPM Pariaman didukung dengan biaya operasional yang berasal dari APBN sebesar 18 Milyar dan dana BOS sebesar 635.000.000,- tahun 2017 serta dana masyarakat. Dengan dukungan dana yang besar SUPM Pariaman memiliki fasilitas dan peralatan yang lengkap dan menyediakan perumahan untuk Kepala Sekolah dan Guru disamping asrama untuk peserta didik.

Disamping itu SUPM juga memiliki unit produksi yang dikembangkan melalui sistem teaching factory (TEFA) yakni unit produksi tambak udang, unit produksi budidaya ikan tawar, ikan payau dan ikan hias, serta unit produksi olahan ikan yang pemasaran unit produksi ini telah mencapai wilayah Sumatera Barat. Fasilitas peralatan dan pembiayaan yang memadai ditambah guru-guru produktif yang telah memiliki sertifikasi dan kompetensi keahlian sesuai standar IMO, sehingga sekolah SUPM Pariaman sebagai barometer pembanding bagi SMK kemaritiman di Sumatera Barat.

\section{Kondisi SMKN Kemaritiman (Sarana dan Prasarana, Guru dan Pembiayaan)}

\section{Sarana dan Prasarana dan Guru}

Kondisi SMK Kemaritimanan di Sumatera Barat, selain SMKN 3 Pariaman yang telah terakreditasi BNSP dan diakui oleh UP-Proval Perhubungan Laut kondisi sarana dan prasarana hanya perlu dikuatkan pada Laboratorium Bahari saat ini agak terbengkalai, sedangkan SMK Kemaritiman lainnya (SMKN Tanjung Mutiara Agam, SMKN 2 Painan, SMKN Sasak Pasaman Barat dan SMKN 10 Padang) belum memenuhi pelayanan pendidikan yang berkualitas 
bidang kemaritiman sebagaimana yang disyaratkan standar Up-Proval dari Direktorat Jenderal Perhubungan Laut serta standar IMO. Seperti ketersediaan sarana dan prasarana menunjang kompetensi siswa seperti ketersediaan (fisika, Kimia dan biologi); laboratorium pengolahan; ruang fishing gear; bengkel latih; peralatan BST; kolam ikan tawar dan payau serta kapal latih ketersediaanya belum sesuai dengan standar ditambah kondisinya yang tidak terawat, tempat yang tidak luas dan jumlah peralatan tidak sesuai dengan jumlah siswa praktek.

Untuk ketersediaan guru produktif yang memiliki kompetensi bidang kelautan terdapat 3 (tiga) SMKN yang tidak memiliki guru produktif yang memiliki kompetensi kelautan yakni SMKN Sasak Pasaman Barat, SMKN Tanjung Mutiara dan SMKN 2 Painan, sehingga sekolah mendatangkan guru produktif dari SUPM Pariaman dan dari Perguruan Tinggi (Univ. Bung Hatta).

\section{Pembiayaan}

Dari hasil dan kondisi terkait pembiayaan operasional sekolah bersumber dari dana BOP dan BOS tidak mencukupi, hal ini terlihat dari 5 (lima) sekolah kemaritiman di
Sumatera Barat jauh dari standar yang ditetapkan, umumnya ruangan labor, whorkshop, peralatan utama dan peralatan pendukung rata-rata tidak memenuhi standar. Dan juga pembiayaan personalia maupun non personalia sangat kecil dibanding dengan SUPM. Seharusnya sebagai sekolah kemaritiman atau sekolah yang membuka bidang kemaritiman perlu dukungan dana yang besar, karena harus memiliki gedung, labor, bengkel, alat dan peralatan dan juga kapal yang terstandar sesuai yang dipersyaratkan dirjen perhubungan laut dan IMO. Sedangkan anggaran pembangunan fisik sekolah melalui dana alokasi khusus (DAK), sangat terbatas dan proses mendapatkannya harus membuat profosal yang jelas itupun tidak semua sekolah yang mendapatkanya, sama dengan dana fokir dari dewan sekolah bersaing mendapatkan dana tersebut, sehingga yang terlihat banyak gedung, tidak layak, bengkel yang tidak standar, mesin dan peralatan yang tidak cukup dan juga sudah tua.

Berdasarkan Permendiknas No. 69 th 2009 tentang standar biaya operasi non personalia di bedakan menurut bidang/program keahlianya dan mengacu kepada pada standar DKI 
Jakarta. Kalau kita lihat dari dana BOS atau BOP yang diterima lima sekolah tersebut masih kecil jika dibanding dengan kebutuhan biaya pendidikan khususnya bidang kemaritiman. Dari penelitian yang dilakukan pada lima SMK Negeri kemaritiman di Sumatera Barat, peneliti mendapatkan data dari observasi dilapangan dengan melihat langsung kondisi sekolah yang terkait 8 standar nasional pendidikan banyak tidak memenuhi standar, baik gedung, bengkel, labor dan juga peralatan. Standar Pembiayaan yang diamanatkan oleh PP No 32 tahun 2013 yang perubahan dari PP No 19 tahun 2005 dilihat dilapangan belum mencukupi untuk memenuhi skema pembiayaan pendidikan menengah apalagi untuk pembiayaan sekolah kemaritiman. Kalau dibandingan dengan skema pembiayaan di SMK Negeri dengan SUPM Pariaman jauh berbeda, jauh lebih besar anggaran SUPM Pariaman. Dibanding dengan SMK negeri khusus bidang kemaritiman.

\section{Pembahasan}

Kondisi Idealnya sekolah
kejuruan, untuk menjadikan seorang
memiliki kompetensi di bidang
kejuruan maka antara pelajaran teori
dan praktek ratio $30 \%$ teori : $70 \%$

praktek. Hal ini tidak bisa dilaksanakan karena belum semua SMK Kemaritiman memiliki sarana utama untuk praktek. Hal inilah yang menjadi persoalan selama ini bagi SMK Kemaritiman di Sumatera Barat dalam mewujudkan SDM yang handal.

Untuk menjawab persoalan tersebut pemerintah mengeluarkan Inpres No. 9 Tahun 2016 tentang Revitalisasi Sekolah Menengah Kejuruan dalam rangka peningkatan kualitas dan Daya Saing Sumber Daya Manusia. Instruksi dalam revitalisasi ditujukan kepada 12 Menteri Kabinet Kerja, 34 Gubernur, dam Kepala Badan Nasional Sertifikasi Profesi, berisi tentang:

1. Mengambil langkah-langkah yang diperlukan sesuai tugas, fungsi, dan kewenangan masing-masing untuk merevitalisasi SMK guna meningkatkan kualitas dan daya saing sumber daya manusia Indonesia.

2. Menyusun peta kebutuhan tenaga kerja bagi lulusan SMK sesuai tugas, fungsi dan kewenangan masingmasing dengan berpedoman pada peta jalan pengembangan SMK. 10 (sepuluh) langkah revitalisasi SMK

1. Revitalisasi SDM 
2. Membangun SAS berbasis SIM

3. Link And Macht dengan Industri

4. Kurikulum berbasis Industri

5. Teaching Factory

6. Penggunaan Media Video Tutorial dan Portofolio berbasis Video e-Repor Skill

7. Uji Sertifikasi Profesi

8. Pemenuhan Sarana dan Prasarana

9. Mengembangkan Kearifan lokal

10. Peran SMK sebagai penggerak ekonomi lokal (disadur dari Buku Strategi
Dalam melaksanakan 10 langkah tersebut, SMK harus memahami Area Revitalisasi itu sendiri yaitu: kurikulum, Guru dan Tenaga Kependidikan, Kerjasama dengan Industri, Sertifikasi dam Akreditasi, serta Sarana dan Prasarana dan Kelembagaan.

Berdasarkan data kesenjangan Supply dan Demand Lulusan SMK dari Direktorat Pendidikan Menengah, Kementerian Pendidikan Nasional Tahun 2016 sebagai berikut :

Revitalisasi SMK)

Tabel 1 : Kesenjangan Supply dan Demand Lulusan SMK Dengan Peluang Kebutuhan Tenaga Kerja tahun 2016

\begin{tabular}{|c|c|c|c|c|}
\hline No & Bidang Keahlian & $\begin{array}{l}\text { Lulusan Smk } \\
\text { Tahun } 2016 \\
\end{array}$ & $\begin{array}{l}\text { Peluang Kebutuhan } \\
\text { Tenaga Kerja } \\
\end{array}$ & $\begin{array}{c}\text { Kelebihan (+) } \\
\text { Kekurangan (-) }\end{array}$ \\
\hline \multirow[t]{2}{*}{1} & Teknologi dan Rekayasa & 1 & 611.644 & 170.083 \\
\hline & Teknologi dan Rekayasa & 441.561 & & \\
\hline 2 & Energi dan Pertumbuhan & 3.486 & 27.008 & 23.522 \\
\hline 3 & $\begin{array}{l}\text { Tegnologi Informasi dan } \\
\text { Komunikasi }\end{array}$ & 277.5445 & 327.813 & 50.268 \\
\hline 4 & $\begin{array}{l}\text { Kesehatan dan Pekerjaan } \\
\text { Sosial }\end{array}$ & 60.944 & 68.245 & 7.301 \\
\hline 5 & $\begin{array}{l}\text { Agribisnis dan Agro } \\
\text { Tehnologi }\end{array}$ & 52.319 & 445.792 & 393.473 \\
\hline 6 & Kemaritiman & 17.249 & 3.364.297 & -3.347 .048 \\
\hline 7 & Bisnis dan Manajemen & 348.954 & 119.255 & -299.699 \\
\hline 8 & Pariwisata & 82.171 & 707.600 & 4.463 .541 \\
\hline 9 & Seni dan Industri Kreatif & 12.017 & 88.133 & 76.116 \\
\hline & TOTAL & 1.296 .646 & 5.759 .787 & 4.463 .541 \\
\hline
\end{tabular}

Pada tabel diatas mengindikasi bahwa bidang keahlian kemaritiman memiliki kesenjangan yang signifikan antara demand dan supply, hal ini terlihat SMK Kemaritiman hanya mampu mencetak lulusan sebanyak 17.249 peserta didik, sedangkan peluang kebutuhan tenaga kerja 3.364.297 sehingga ketersediaan kebutuhan tenaga kerja bidang kemartiman minus $(-3.347 .048)$ hal ini mengindikasikan tingginya kebutuhan dunia usaha/industri terhadap lulusan SMK Kemaritiman. 
Kesenjangan kompetensi antara kompetensi belajar di SMK dan kompetensi yang diperlukan dalam pasar kerja mendapatkan perhatian dari Pemerintah dalam bentuk perubahan kurikulum dengan cara penyelarasan kurikulum di sekolah dengan kebutuhan Dunia Usaha/Industri. Selain itu Pemerintah juga akan melakukan tata ulang program keahlian yang memang sudah tidak sesuai dengan program keahlian baru yang sesuai dengan kebutuhan perkembangan Dunia Usaha/Industri saat ini.

Rencana ini disambut baik oleh masyarakat khususnya Dunia Usaha dan Industri yang membantu dalam pelaksanaan kurikulum sekolah dalam bentuk kerjasama industri. Terbukti dengan pertumbuhan SMK semakin pesat di Indonesia dan peminatnya semakin banyak dari tahun ke tahun. Hal tersebut terbukti dengan semakin banyak orang tua menyekolahkan anaknya pada jenjang pendidikan SMK. Masyarakat menyadari pentingnya pendidikan SMK sebagai lembaga yang mencetak tenaga-tenaga terampil siap kerja dalam menghadapi perkembangan dunia global yang semakin pesat. Selain itu pilihan orang tua untuk menyekolahkan anaknya di SMK didasari oleh anggapan bahwa orang tua akan lebih cepat balik modal karena SMK menyiapkan lulusan yang siap bekerja. Dari pola pengelolaan, seperti tatakelola SMK kemaritiman perlu distandarkan satu sama lainnya, sehingga masing-masing sekolah saling bersinergi satu sama lainnya, seperti yang terdapat pada SUPM Padang Pariaman yang langsung dibawah Kementerian Kelautan Republik Indonesia (RI).

\section{KESIMPULAN}

Untuk peningkatan kualitas SMK Kemaritiman ditinjau dari 3 (tiga) aspek:

1. Perlu peningkatan Sarana dan Prasarana

$$
\text { Sebagaimana yang telah }
$$
dijelaskan pada halaman sebelumnya bahwa pembelajaran kejuruan yang berkualitas minimal antara teori dan Praktek ratio $30 \%$ teori berbanding $70 \%$ praktek. Kondisi saat ini rata-rata SMK Kemaritiman belum bisa mewujudkannya. Untuk itu perlu sarana praktek yang memadai baik itu berupa kapal latih operasional maupun simulator (Nautika dan Engine). Kapal latih operasional yang dimaksudkan, memiliki peralatan yang memadai untuk dilatihkan kepada peserta didik secara 
menyeluruh terhadap kompetensi yang harus dikuasai sesuai kejuruan dan sekaligus dapat dioperasikan dalam keadaan yang sesungguhnya mulai dari perencanaan, persiapan operasional, operasional, pasca operasional dan sampai pada pemasaran hasil.

2. Perlu peningkatan Kuantitas dan Kualitas Guru dan Tenaga Kependidikan

Mengenai kuantitas dan kualitas, hal ini terkait dengan SDM dan Sarana dan prasarana. Kuantitas SDM tenaga pendidik dan tenaga kependidikan pada setiap SMK Kemaritiman saat ini dapat diminimalisir dengan semangat program KG (Keahlian Ganda). Sedangkan untuk SDM tenaga pendidik yang berkualitas dapat dilakukan dengan meningkatkan program magang yang berkelanjutan bagi guru kejuruan terkait sehingga hasilnya dapat dibuktikan dengan sertifikat yang diperoleh dan kualitas pembelajaran yang dapat dipantau melaui supervisi oleh Kepala sekolah.

\section{Perlu Peningkatan Pembiayaan}

Mengenai pembiayaan, hal ini adalah sesuatu yang mutlak. Apabila harus dipenuhi semua peralatan yang di syaratkan maka semua pihak dapat hendaknya menyadari bahwa peralatan utama kemaritiman adalah barang impor dengan standar harga Dolar Amerika. Untuk kompetensi kelautan/Up-Proval ini adalah suatu persyaratan yang harus dipenuhi oleh Setiap SMK, karena apabila tidak bisa dipenuhi maka peserta didik dari SMK yang bersangkutan tidak boleh mengikuti Uji sertifikasi kepelautan (contoh ANKAPIN dan ATKAPIN)

\section{REKOMENDASI}

1. Melakukan kerjasama dengan Dunia Industri terkait, untuk mengatasi kekurangan sarana dan prasarana malalui rekomendasi Pemerintah Provinsi Sumatera Barat;

2. Mengoptimalkan pemanfaatan sarana dan prasarana yang ada melalui kolaborasi antar SMK dengan bidang kejuruan yang sama;

3. Menjadikan tenaga pendidik honorer yang telah memiliki masa pengabdian yang disyaratkan diangkat sebagai ASN dan meningkatkan komptensinya melalui pelatihan keahlian serta;

4. Memberikan pembiayaan yang memadai agar menghasilkan SDM Kemaritiman yang handal.

5. Masing-masing SMK perlu melakukan sinergi dalam pengadaan laboratorium keahlian, sehingga 
masing-masing SMK mempunyai

yang dimiliki.

keunggulan tersendiri dari kekuatan

\section{DAFTAR PUSTAKA}

Adesa, 2016. Tindak Lanjut Program

Pendidikan Vokasi.

Ari, 2016. Kemdikbud Kembangkan

Empat Jenis SMK.

Johan, A.B. 2014. Peran Pendidikan

Kejuruan dalam Menghadapi

Masyarakat Ekonomi ASEAN

(MEA). Journal.ustjogja.ac.id,

diakses pada tanggal 18 Oktober

2016. Poerwadarminta, W.J.S.

2003. Kamus Umum Bahasa

Indonesia edisi Ketiga.Balai

Pustaka Jakarta.

Rasto, 2012. Pendidikan Kejuruan.

Pendidikan_Manajemen_Perkanto ran,

Salinan Inpres Nomor 9 Tahun 2016.

Tentang revitalisasi sekolah

menengah kejuruan,
Salinan Undang-Undang Nomor 20

Tahun 2003 Tentang Sistim

Pendidikan Nasional. .

Salinan Undang-Undang Nomor 23

Tahun 2014 Tentang Pemerintah

Daerah.

Salinan Peraturan Pemerintah Nomor

29 Tahun 1990.

Sugiyono. 2013. Konsep Dasar

Pendidikan Kejuruan

Disampaikan Pada Bimtek Lomba

Karya Ilmiah Inovasi

Pembelajaran Bagi Guru

Produktif Smk. Kementerian

Pendidikan Dan Kebudayan

Direktorat Jenderal Pendidikan

Menengah Direktorat Pembinaan

Ptk Dikmen tahun 2013. 